University of Wollongong

Research Online

Faculty of Engineering and Information

Faculty of Engineering and Information

Sciences - Papers: Part A

Sciences

$1-1-2012$

Correlating uncompensated antiferromagnetic moments and exchange coupling interactions in interface ion-beam bombarded Co90Fe 10/CoFeoxide bilayers

Chin Shueh

National Chung Hsing University, Taiwan

Pei-Shi Chen

National Chung Hsing University, Taiwan

David Cortie

University of Wollongong, dlc422@uowmail.edu.au

Frank Klose

ANSTO, Frank.Klose@ansto.gov.au

Wen-Chen Chen

National Yunlin University Of Science And Technology, Taiwan

See next page for additional authors

Follow this and additional works at: https://ro.uow.edu.au/eispapers

Part of the Engineering Commons, and the Science and Technology Studies Commons

Research Online is the open access institutional repository for the University of Wollongong. For further information contact the UOW Library: research-pubs@uow.edu.au 


\title{
Correlating uncompensated antiferromagnetic moments and exchange coupling interactions in interface ion-beam bombarded Co90Fe 10/CoFe-oxide bilayers
}

\begin{abstract}
The coercivity and exchange bias field of ferro-/antiferromagnetic Co 90Fe10/CoFe-oxide bilayers were studied as function of the surface morphology of the bottom CoFe-oxide layer. The CoFe-oxide surface structure was varied systematically by low energy (0-70 V) Argon ion-beam bombardment before subsequent deposition of the Co90Fe10 layer. Transmission electron microscopy results showed that the bilayer consisted of hcp Co90Fe10 and rock-salt CoFe-oxide. At low temperatures, enhanced coercivities and exchange bias fields with increasing ion-beam bombardment energy were observed, which are attributed to defects and uncompensated moments created near the CoFe-oxide surface in increasing amounts with larger ion-beam bombardment energies. Magnetometry results also showed an increasing divergence of the low field temperature dependent magnetization $[\Delta \mathrm{M}(\mathrm{T})]$ between field-cooling and zerofield-cooling processes, and an increasing blocking temperature with increasing ion-beam bombardment energy. (c) 2012 The Japan Society of Applied Physics.
\end{abstract}

\section{Keywords}

correlating, moments, exchange, bilayers, oxide, interactions, coupling, cofe, antiferromagnetic, 10, co90fe, bombarded, beam, ion, interface, uncompensated

Disciplines

Engineering | Science and Technology Studies

\section{Publication Details}

Shueh, C., Chen, P., Cortie, D., Klose, F., Chen, W., Wu, T. H., Van Lierop, J. \& Lin, K. (2012). Correlating uncompensated antiferromagnetic moments and exchange coupling interactions in interface ion-beam bombarded Co90Fe 10/CoFe-oxide bilayers. Japanese Journal of Applied Physics, 51

11PG02-1-11PG02-4.

\section{Authors}

Chin Shueh, Pei-Shi Chen, David Cortie, Frank Klose, Wen-Chen Chen, T H. Wu, Johan Van Lierop, and KoWei Lin 
Correlating Uncompensated Antiferromagnetic Moments and Exchange Coupling Interactions in Interface Ion-Beam Bombarded $\mathrm{Co}_{90} \mathrm{Fe}_{10} / \mathrm{CoFe}-O x i d e$ Bilayers

Chin Shueh $^{1}$, Pei-Shi Chen ${ }^{1}$, David Cortie ${ }^{2,3}$, Frank Klose ${ }^{3}$, Wen-Chen Chen ${ }^{4}$, Te-Ho $\mathrm{Wu}^{4}$, Johan van Lierop ${ }^{5}$, and Ko-Wei Lin ${ }^{1, *}$

${ }^{1}$ Department of Materials Science and Engineering, National Chung Hsing University, Taichung 402, Taiwan

${ }^{2}$ Institute for Superconducting and Electronic Materials, University of Wollongong, Wollongong 2522, Australia

${ }^{3}$ Australian Nuclear Science and Technology Organisation, Kirrawee 2232, Australia

${ }^{4}$ Taiwan Spin Research Center, National Yunlin University of Science and Technology, Douliu 640, Taiwan

${ }^{5}$ Department of Physics and Astronomy, University of Manitoba, Winnipeg R3T 2N2, Canada

*Corresponding author. E-mail address: kwlin@dragon.nchu.edu.tw 


\section{Abstract}

The coercivity and exchange bias field of ferro-/antiferromagnetic $\mathrm{Co}_{90} \mathrm{Fe}_{10} /$ CoFe-oxide bilayers were studied as function of the surface morphology of the bottom CoFe-oxide layer. The CoFe-oxide surface structure was varied systematically by low energy $(0-70 \mathrm{~V})$ Argon ion-beam bombardment before subsequent deposition of the $\mathrm{Co}_{90} \mathrm{Fe}_{10}$ layer. Transmission electron microscopy results showed that the bilayer consisted of hcp $\mathrm{Co}_{90} \mathrm{Fe}_{10}$ and rock-salt $\mathrm{CoFe}$-oxide. At low temperatures, enhanced coercivities and exchange bias fields with increasing ion-beam bombardment energy were observed, which are attributed to defects and uncompensated moments created near the CoFe-oxide surface in increasing amounts with larger ion-beam bombardment energies. Magnetometry results also showed an increasing divergence of the low field temperature dependent magnetization $[\Delta \mathrm{M}(\mathrm{T})]$ between field-cooling and zero-field-cooling processes, and an increasing blocking temperature with increasing ion-beam bombardment energy. 


\section{Introduction}

Exchange bias [1-6], i.e., the shift of the hysteresis loop of a ferromagnetic (FM) material in contact with an antiferromagnetic (AFM) material after a field-cooling process, depends on many factors including the particular materials involved [7-10], film growth conditions [11-14], the structural, compositional and magnetic details of the interfaces [15-18], the magnetic stiffness of the AFM moments, and the field-cooling conditions [19-22].

In this work, we varied the structural and magnetic interface between FM and AFM $\mathrm{Co}_{90} \mathrm{Fe}_{10} / \mathrm{CoFe}$-oxide bilayers by bombarding the surface of the bottom AFM CoFe-oxide layer with Argon ions of varying energy before the subsequent growth of the top $\mathrm{FM} \mathrm{Co}_{90} \mathrm{Fe}_{10}$ layer. We observed a systematic increase of the coercivity and exchange bias at low temperature as function of the Ar ion-beam energy, which we attributed to an increase in the creation of defects and uncompensated moments in the AFM layer from higher ion-beam energies.

\section{Experimental Methods}

The $\mathrm{Co}_{90} \mathrm{Fe}_{10}(\mathrm{at} \%) / \mathrm{CoFe}-$ oxide bilayers were prepared on oxidized $\mathrm{Si}$ wafer substrates by using a dual ion-beam sputtering deposition technique [21,22]. A Kaufman ion source $(800 \mathrm{~V}, 7.5 \mathrm{~mA})$ was used to focus an Argon ion-beam onto a commercial $\mathrm{Co}_{90} \mathrm{Fe}_{10}$ target surface in order to fabricate the top $\mathrm{Co}_{90} \mathrm{Fe}_{10}$ layer. An End-Hall ion source $\left(\mathrm{V}_{\mathrm{EH}}=100 \mathrm{~V}, 500 \mathrm{~mA}\right)$ was used to in-situ bombard the growing bottom layer 
during deposition with a mixture of $41 \% \mathrm{O}_{2} / \mathrm{Ar}\left(\mathrm{O}_{2} / \mathrm{Ar}\right.$ flow rate: $\left.1.6 / 2.3 \mathrm{sccm}\right)$ in order to fabricate the bottom CoFe-oxide layer (17 nm nominal thickness). Before capping with the top $\mathrm{Co}_{90} \mathrm{Fe}_{10}$ layer (23 $\mathrm{nm}$ nominal thickness), the surface of the CoFe-oxide layer was bombarded by $100 \%$ Ar ions using the same End-Hall source. The acceleration voltage $\left(\mathrm{V}_{\mathrm{EH}}\right)$ was varied from 40 to $70 \mathrm{~V}$ for different films in order to create varying surface microstructure on the CoFe-oxide layer.

\section{Results and Discussion}

The microstructures of the $\mathrm{Co}_{90} \mathrm{Fe}_{10}(\sim 17 \mathrm{~nm}) /$ CoFe-oxide $(\sim 23 \mathrm{~nm})$ bilayers were characterized by TEM (Transmission Electron Microscopy), as shown in Fig. 1. The un-bombarded $\left(\mathrm{V}_{\mathrm{EH}}=0 \mathrm{~V}\right) \mathrm{Co}_{90} \mathrm{Fe}_{10} / \mathrm{CoFe}$-oxide bilayers were polycrystalline with grain sizes ranging from 5 to $15 \mathrm{~nm}$. The respective electron diffraction patterns [Fig. 1(a)] indicated that the bilayers consisted of hcp $\mathrm{Co}_{90} \mathrm{Fe}_{10}(\mathrm{a} \sim 2.5 \AA, \mathrm{c} \sim 4.1 \AA)$ and rock-salt CoFe-oxide (a $4.2 \AA$ ), in agreement with our previous works [22,23] on these CoFe-based film systems. The bombardment of the bottom CoFe-oxide layer surface with low-energy Ar ion-beams $\left(\mathrm{V}_{\mathrm{EH}}=40\right.$ to $\left.70 \mathrm{~V}\right)$ neither changed the crystal structure nor altered significantly the grain size distribution close to the CoFe-oxide surface, as revealed by the TEM images and diffraction patterns shown in Figs. 1(c) and 1(d) for $\mathrm{Co}_{90} \mathrm{Fe}_{10} /$ CoFe-oxide $\left(\mathrm{V}_{\mathrm{EH}}=50 \mathrm{~V}\right)$ and Figs. 1(e) and 1(f) for $\mathrm{Co}_{90} \mathrm{Fe}_{10} /$ CoFe-oxide $\left(\mathrm{V}_{\mathrm{EH}}=70 \mathrm{~V}\right)$. As can be seen in the cross-sectional TEM images in Figs. 1(b), 1(d) and 1(f), all $\mathrm{Co}_{90} \mathrm{Fe}_{10} / \mathrm{CoFe}$-oxide bilayers exhibited a smooth interface with roughnesses 
considerably below $2 \mathrm{~nm}$. It can be concluded from the data presented in Fig. 1 that the low-energy ion-beam bombardment did not lead to significant microstructural and morphological variations (lattice constant, grain size, roughness, and interface flatness) in the AF CoFe-oxide layer.

The room temperature hysteresis loops of the different $\mathrm{Co}_{90} \mathrm{Fe}_{10} / \mathrm{CoFe}$-oxide bilayers made with Ar ion-beam bombardment voltages, $\mathrm{V}_{\mathrm{EH}}=0$ to $70 \mathrm{~V}$, are shown in Fig. 2. Since $\mathrm{Co}_{90} \mathrm{Fe}_{10}$ is a ferromagnet $\left(\mathrm{T}_{\mathrm{c}}\right.$, bulk $\sim 1800 \mathrm{~K}$ [24]) and CoFe-oxide is an antiferromagnet with a Néel temperature less than that of $\mathrm{CoO}\left(\mathrm{T}_{\mathrm{N}}\right.$, bulk $\left.\sim 290 \mathrm{~K}[25]\right)$, no exchange bias effects were expected at room temperature. The $\mathrm{Co}_{90} \mathrm{Fe}_{10} / \mathrm{CoFe}$-oxide bilayer without ion-beam bombardment $\left(\mathrm{V}_{\mathrm{EH}}=0 \mathrm{~V}\right)$ exhibited a square hysteresis loop with a high remanence magnetization, $\mathrm{M}_{\mathrm{r}}$, and a coercivity of $\mathrm{H}_{\mathrm{c}} \sim 15 \mathrm{Oe}$, as is shown in Fig. 2(a). Increasing the ion-beam bombardment energy [Fig. 2(b)] resulted in a systematic decrease of $\mathrm{M}_{\mathrm{r}}$, while $\mathrm{H}_{\mathrm{c}}$ remained unaffected ( 20 Oe).

The decrease in $\mathrm{M}_{\mathrm{r}}$ with increasing $\mathrm{V}_{\mathrm{EH}}$ indicates that the ion-beam bombardment of the bottom CoFe-oxide layer may have created defects that influenced strongly the magnetization reversal processes in the $\mathrm{Co}_{90} \mathrm{Fe}_{10}$ layer. Since the CoFe-oxide layer is believed to be paramagnetic at $298 \mathrm{~K}$, structural defects [26] must have been responsible for the low $\mathrm{M}_{\mathrm{r}}$ values of the ion-bombarded samples.

To study exchange bias effects, the $\mathrm{Co}_{90} \mathrm{Fe}_{10} / \mathrm{CoFe}$-oxide bilayers were $12 \mathrm{kOe}$ field-cooled from 350 to $50 \mathrm{~K}$. The hysteresis loops for the films after field cooling are shown in Fig. 2(c). In contrast to the room temperature behavior, for all $\mathrm{V}_{\mathrm{EH}}$ 
bombardment energies, a square and symmetric loop shape was present, and a high remanence concomitant with the square loops, i.e. $M_{r} / M_{s} \sim 1$. Figure 2(c) identifies clearly that an increasing exchange bias field $\left(\mathrm{H}_{\mathrm{ex}}\right)$ developed with increasing ion-beam bombardment energy. The dependence of $\mathrm{H}_{\mathrm{c}}$ and $\mathrm{H}_{\mathrm{ex}}$ on $\mathrm{V}_{\mathrm{EH}}$ [Fig. 2(d)] shows that without ion-beam bombardment, $\mathrm{H}_{\mathrm{ex}} \sim-150$ Oe and $\mathrm{H}_{\mathrm{c}} \sim 250$ Oe was measured, and for increasing $\mathrm{V}_{\mathrm{EH}}$ values up to $70 \mathrm{~V}$ a monotonic increase of $\mathrm{H}_{\mathrm{c}}$ and $\mathrm{H}_{\mathrm{ex}}$ resulted. These trends contrast those observed in a previous study on films of similar composition with modifications of the interface [23]. Using much higher ion-beam bombardment energies of $\mathrm{V}_{\mathrm{EH}}=70-150 \mathrm{~V}$, caused greater damage to the $\mathrm{AF}$ spin configuration in the CoFe-oxide layer and increased in the degree of misalignment [27,28], which resulted in a decrease of $\mathrm{H}_{\mathrm{ex}}$. In addition, the linear increase of $\mathrm{H}_{\mathrm{c}}$ vs $\mathrm{V}_{\mathrm{EH}}$ in the $\mathrm{Co}_{90} \mathrm{Fe}_{10} /$ CoFe-oxide bilayers in this study indicates that an enhancement of the $\mathrm{Co}_{90} \mathrm{Fe}_{10}$ anisotropy could be achieved by coupling to the defects created by ion-beam bombardment on the AF CoFe-oxide surface that act as pinning sites of domains during the magnetization reversal processes [21].

Further evidence of the nature of the exchange coupling between the $\mathrm{Co}_{90} \mathrm{Fe}_{10}$ and CoFe-oxide layer is evident in the temperature dependence of the zero field-cooled (ZFC) and field-cooled (FC) DC susceptibility (M vs T) data measured with a Quantum Design VSM using $100 \mathrm{Oe}$, as shown in Fig. 3. The difference in the ZFC/FC curves is small (e.g., consider the $\Delta \mathrm{M}_{\mathrm{FC}-\mathrm{ZFC}}$ in Fig. 4) in $\mathrm{Co}_{90} \mathrm{Fe}_{10} / \mathrm{CoFe}$-oxide bilayers without $\left(\mathrm{V}_{\mathrm{EH}}=0\right.$ $\mathrm{V})$ or with low energy ion-beam bombardment $\left(\mathrm{V}_{\mathrm{EH}}=40\right.$ and $\left.50 \mathrm{~V}\right)$. However, a 
significant increase in the ZFC moment with increasing temperature from 50 to $300 \mathrm{~K}$ was observed for the largest $\mathrm{V}_{\mathrm{EH}}=70 \mathrm{~V}$ [Fig. 3]. This parallels the change in the ferromagnetic response as a function of temperature, and is a signature of the exchange coupling between the $\mathrm{Co}_{90} \mathrm{Fe}_{10}$ and the CoFe-oxide layer, identified by its larger $\mathrm{H}_{\mathrm{ex}}$. Note that a similar effect was also observed in $\mathrm{NiFe} / \mathrm{NiFeO}$ thin films [29]. The blocking temperature, $T_{B}$, estimated by the magnetization with a maximum in the ZFC scan [29], was found to increase with increasing $\mathrm{V}_{\mathrm{EH}}$ from $180 \mathrm{~K}\left(\mathrm{~V}_{\mathrm{EH}}=0 \mathrm{~V}\right)$ to $230 \mathrm{~K}\left(\mathrm{~V}_{\mathrm{EH}}=70\right.$ V), as shown in the inset of Fig. 3.

Our previous work on $\mathrm{NiFe} / \mathrm{NiO}$ bilayers [21] has shown that the pure ferromagnetic (e.g., permalloy) layer usually exhibited identical ZFC and FC curve with $\mathrm{H}_{\text {app }}=100 \mathrm{Oe}$ (i.e. $\Delta \mathrm{M}_{\mathrm{FC}-\mathrm{ZFC}}(\mathrm{T})=0$ ), while the coupling of the FM layer with an AFM layer like $\mathrm{NiO}$ will result in a clear divergence between $\mathrm{M}_{\mathrm{ZFC}}(\mathrm{T})$ and $\mathrm{M}_{\mathrm{FC}}(\mathrm{T})$. In the present study, a similar behavior was found in which the degree of divergence $\left(\Delta \mathrm{M}_{\mathrm{FC}-\mathrm{ZFC}}\right)$ seems to depend strongly on the ion-beam modification of exchange bias, as demonstrated by the increase of $\Delta \mathrm{M}_{\mathrm{FC}-\mathrm{ZFC}}\left(\right.$ at $50 \mathrm{~K}$ ) with increasing $\mathrm{V}_{\mathrm{EH}}$, as shown in Fig. 4.

The degree of exchange coupling is qualitatively estimated by the difference in magnetization $(\Delta)[29]$ between $\mathrm{FC}$ and $\mathrm{ZFC}$ at $50 \mathrm{~K}$, which is about $3 \%$ in a spin (or cluster) glass [30] and about $0.5 \%$ in a pure permalloy layer [29]. The $\mathrm{Co}_{90} \mathrm{Fe}_{10} /$ CoFe-oxide $\left(\mathrm{V}_{\mathrm{EH}}=70 \mathrm{~V}\right)$ bilayer exhibited the largest difference in magnetic moment $(\Delta \sim$ $40 \%)$, compared to those of $\Delta(<10 \%)$ in the $\mathrm{Co}_{90} \mathrm{Fe}_{10} / \mathrm{CoFe}$-oxide bilayers with CoFe-oxide surface being bombarded by lower energies (40 and $50 \mathrm{~V}$ ) or without 
bombardment $(\Delta \sim 3 \%)$. The $\mathrm{Co}_{90} \mathrm{Fe}_{10} / \mathrm{CoFe}$-oxide $\left(\mathrm{V}_{\mathrm{EH}}=70 \mathrm{~V}\right)$ bilayer also had the highest exchange bias, and lowest room temperature remanence $\mathrm{M}_{\mathrm{r}}$. Therefore, the difference $(\Delta)$ in magnetic moment at $50 \mathrm{~K}$ between $\mathrm{ZFC}$ and $\mathrm{FC}$ curves is a measure of the onset of exchange coupling between FM $\mathrm{Co}_{90} \mathrm{Fe}_{10}$ and AFM CoFe-oxide, which altered the ferromagnetic properties. Moreover, it is clear that the temperature where this occurred depended on the ion-beam bombardment energy, implying the formation of differing amounts of stable uncompensated AF CoFe-oxide moments with differing ion doses.

\section{Conclusions}

Low-energy Ar ion-beam bombardment was used to modify the exchange bias effects of $\mathrm{Co}_{90} \mathrm{Fe}_{10} / \mathrm{CoFe}$-oxide bilayers. At low temperature, the $\mathrm{Co}_{90} \mathrm{Fe}_{10} / \mathrm{CoFe}$-oxide bilayers exhibited an almost linear increase of coercivity and exchange bias field with increasing Ar ion-beam bombardment energy on the bottom CoFe-oxide surface. This indicated that the ion-beam bombardment of the CoFe-oxide surface created defects that acted as pinning sites to affect the magnetization reversal processes in $\mathrm{Co}_{90} \mathrm{Fe}_{10}$, thus resulting in coercivity enhancements. This process also promoted the formation of thermally-stable uncompensated moments near the surface of the bottom CoFe-oxide layer that permitted exchange bias loop shifts. 
Acknowledgments

The research was supported by ANSTO of Australia, NSERC of Canada, and NSC of Taiwan.

References

[1] R. L. Stamps: J. Phys. D: Appl. Phys. 33 (2000) R247.

[2] J. Nogues, J. Sort, V. Langlais, V. Skumryev, S. Surinach, J. S. Munoz, and M. D. Baro: Phys. Rep. 422 (2005) 65.

[3] K. O’Grady, L. E. Fernandez-Outon, and G. Vallejo-Fernandez: J. Magn. Magn. Mater. 322 (2010) 883.

[4] A. E. Berkowitz and K. Takano: J. Magn. Magn. Mater. 200 (1999) 552.

[5] M. Kiwi: J. Magn. Magn. Mater. 234 (2001) 584.

[6] N. C. Koon: Phys. Rev. Lett. 78 (1997) 4865.

[7] D. L. Cortie, K.-W. Lin, C. Shueh, H.-F. Hsu, X. L. Wang, M. James, H. Fritzsche, S. Bruck, and F. Klose: Phys. Rev. B 86 (2012) 054408.

[8] T. Saerbeck, F. Klose, D. Lott, G. J. Mankey, Z. Lu, P. R. LeClair, W. Schmidt, A. P. J. Stampfl, S. Danilkin, M. Yethiraj, and A. Schreyer: Phys. Rev. B 82 (2010) 134409. [9] J. Dho, C. W. Leung, Z. H. Barber, and M. G. Blamire: Phys. Rev. B 71 (2005) 180402.

[10] M. R. Fitzsimmons, B. J. Kirby, S. Roy, Z.-P. Li, I. V. Roshchin, S. K. Sinha, and I. K. Schuller: Phys. Rev. B 75 (2007) 214412. 
[11] H. Bea, M. Bibes, F. Ott, B. Dupe, X.-H. Zhu, S. Petit, S. Fusil, C. Deranlot, K. Bouzehouane, and A. Barthelemy: Phys. Rev. Lett. 100 (2008) 017204.

[12] G. Li, C. W. Leung, C. Shueh, H.-F. Hsu, H.-R. Huang, K.-W. Lin, P. T. Lai, and P. W. T. Pong: Surf. Coatings Technol. (in press) [DOI:10.1016/j.surfcoat.2012.05.035].

[13] K.-W. Lin, V. V. Volobuev, J.-Y. Guo, S.-H. Chung, H. Ouyang, and J. van Lierop: J. Appl. Phys. 107, (2010) 09D712.

[14] K.-W. Lin, M.-R. Wei, and J.-Y. Guo: J. Nanosci. Nanotechnol. 9 (2009) 2023.

[15] K.-W. Lin, J.-Y. Guo, S. Kahwaji, S.-C. Chang, H. Ouyang, J. van Lierop, N. N. Phuoc, and T. Suzuki: Phys. Status Solidi A 204 (2007) 3970.

[16] T. Ambrose and C. L. Chien: Appl. Phys. Lett. 65 (1994) 1967.

[17] R. Morales, Z. P. Li, J. Olamit, K. Liu, J. M. Alameda, I. K. Schuller: Phys. Rev. Lett. 102 (2009) 097201.

[18] R. Magaraggia, M. Kostylev, R. L. Stamps, K.-W. Lin, J.-Y. Guo, K.-J. Yang, R. D. Desautels, and J. van Lierop: IEEE Trans. Magn. 47 (2011) 1614.

[19] J. Nogues, D. Lederman, T. Moran, I. K. Schuller: Phys. Rev. Lett. 76 (1996) 3186.

[20] Y. Ijiri, T. C. Schulthess, J. A. Borchers, P. J. van der Zaag, R. W. Erwin: Phys. Rev. Lett. 99 (2007) 147201.

[21] K.-W. Lin, M. Mirza, C. Shueh, H.-R. Huang, H.-F. Hsu and J. van Lierop: Appl. Phys. Lett. 100 (2012) 122409.

[22] K.-W. Lin and J.-Y. Guo: J. Appl. Phys. 104 (2008) 123913. 
[23] C. Shueh, D. L. Cortie, F. Klose, J. van Lierop, and K.-W. Lin: IEEE Trans. Magn. (in press) [DOI: 10.1109/TMAG.2012.2201144].

[24] T. B. Massalski and H. Okamoto: Binary Alloy Phase Diagrams (ASM International, Materials Park, OH, 1990).

[25] R. C. O’Handeley: Modern Magnetic Materials, Principle and Applications (Wiley, New York, 2000).

[26] K.-W. Lin, R. J. Gambino, and L. H. Lewis: J. Appl. Phys. 93 (2003) 6590.

[27] J. McCord, C. Hamann, R. Shafer, L. Schultz, and R. Mattheis: Phys. Rev. B 78 (2008) 094419.

[28] K.-W. Lin, T.-J. Lin, J.-Y. Guo, H. Ouyang, D.-H. Wei, and J. van Lierop: J. Appl. Phys. 105 (2009) 07D710.

[29] K.-W. Lin, R. J. Gambino, and L. H. Lewis: Jpn. J. Appl. Phys. 44 (2005) 3936.

[30] S. Mukherjee, R. Ranganathan, P. S. Anilkumar, and P. A. Joy: Phys. Rev. B 54 (1996) 9267. 
Figure captions

Fig. 1. The planar-view TEM micrographs of the bottom CoFe-oxide layer with Ar ion-beam bombardment on the surface with different energies $\left(\mathrm{V}_{\mathrm{EH}}\right)$ of (a) $0 \mathrm{~V}$, (c) $50 \mathrm{~V}$, and (e) $70 \mathrm{~V}$. The cross-sectional TEM micrographs of the $\mathrm{Co}_{90} \mathrm{Fe}_{10} / \mathrm{CoFe}$-oxide bilayer with the bottom layer bombarded with different $\mathrm{V}_{\mathrm{EH}}$ are shown in (b) $0 \mathrm{~V}$, (d) $50 \mathrm{~V}$, and (f) $70 \mathrm{~V}$, respectively.

Fig. 2. Hysteresis loops of $\mathrm{Co}_{90} \mathrm{Fe}_{10} / \mathrm{CoFe}$-oxide $\left(\mathrm{V}_{\mathrm{EH}}=0,40,50\right.$, and $\left.70 \mathrm{~V}\right)$ bilayers measured at (a) $298 \mathrm{~K}$ and (c) $50 \mathrm{~K}$ (after FC in $12 \mathrm{kOe}$ ). (b) Remanent magnetization $\mathrm{M}_{\mathrm{r}}$ at $298 \mathrm{~K}$ as function of $\mathrm{V}_{\mathrm{EH}}$. (d) Dependence of $\mathrm{H}_{\mathrm{c}}$ and $\mathrm{H}_{\mathrm{ex}}$ on $\mathrm{V}_{\mathrm{EH}}$ at $50 \mathrm{~K}$ after FC.

Fig. 3. The temperature dependence of $\mathrm{ZFC}$ and $\mathrm{FC}$ magnetization of $\mathrm{Co}_{90} \mathrm{Fe}_{10} /$ CoFe-oxide bilayers. The blocking temperature vs $\mathrm{V}_{\mathrm{EH}}$ is shown in the inset.

Fig. 4. The temperature dependence of the difference between ZFC and FC magnetization $\left(\Delta \mathrm{M}_{\mathrm{FC}-\mathrm{ZFC}}\right)$ of $\mathrm{Co}_{90} \mathrm{Fe}_{10} / \mathrm{CoFe}$-oxide bilayers. The $\Delta \mathrm{M}_{\mathrm{FC}-\mathrm{ZFC}}$ at $50 \mathrm{~K}$ vs $\mathrm{V}_{\mathrm{EH}}$ is shown in the inset. 
Fig. 1.
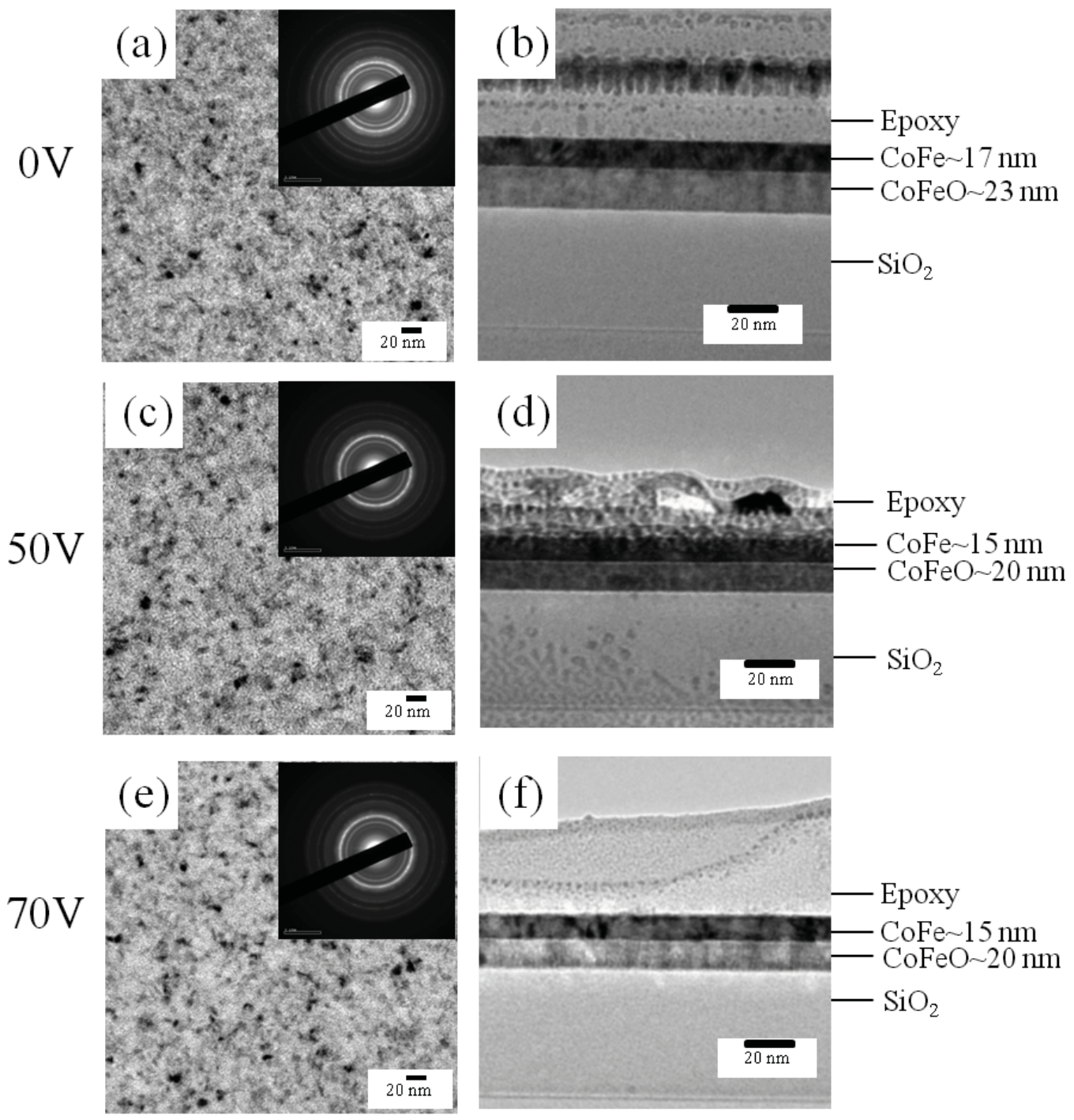
Fig. 2.
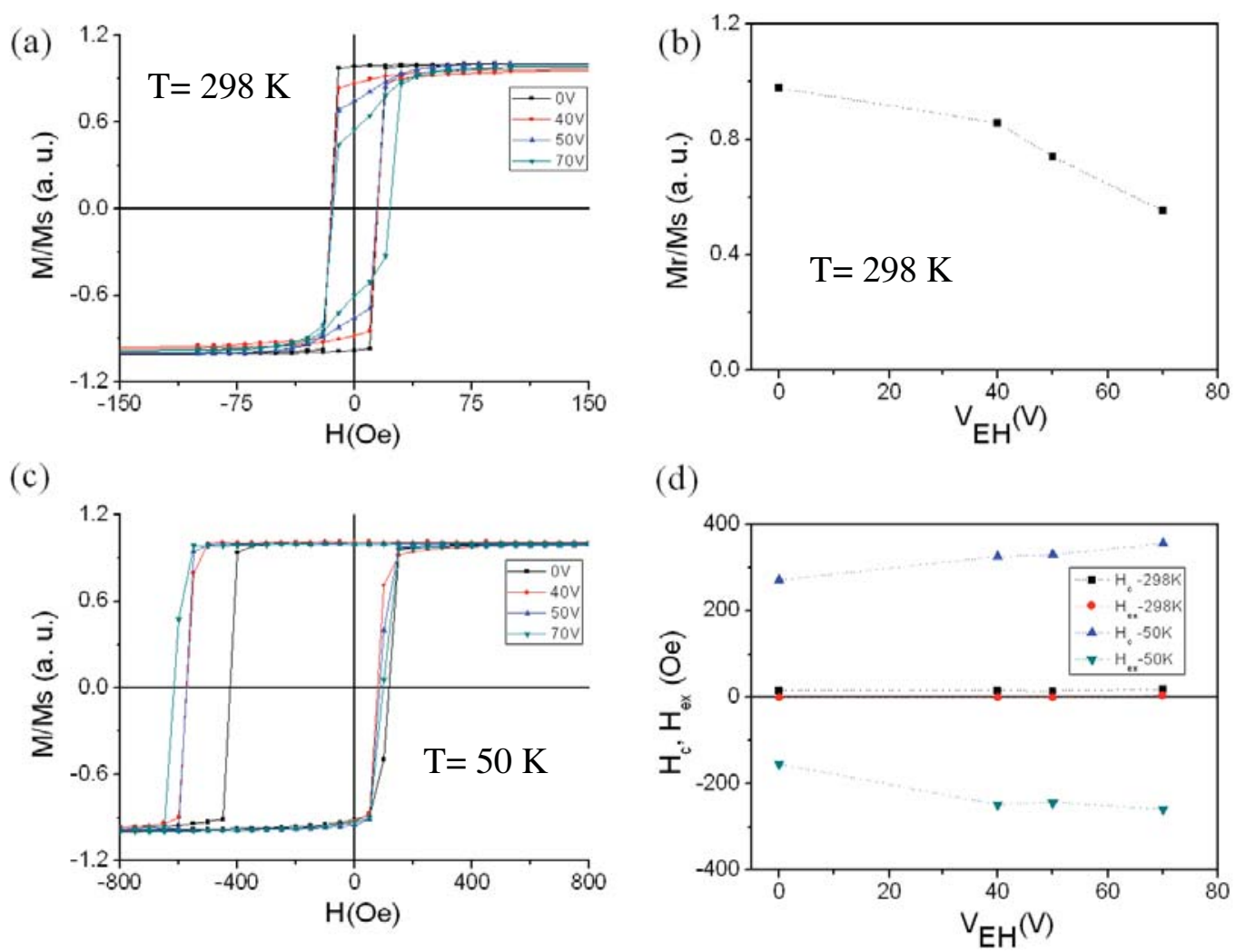
Fig. 3.

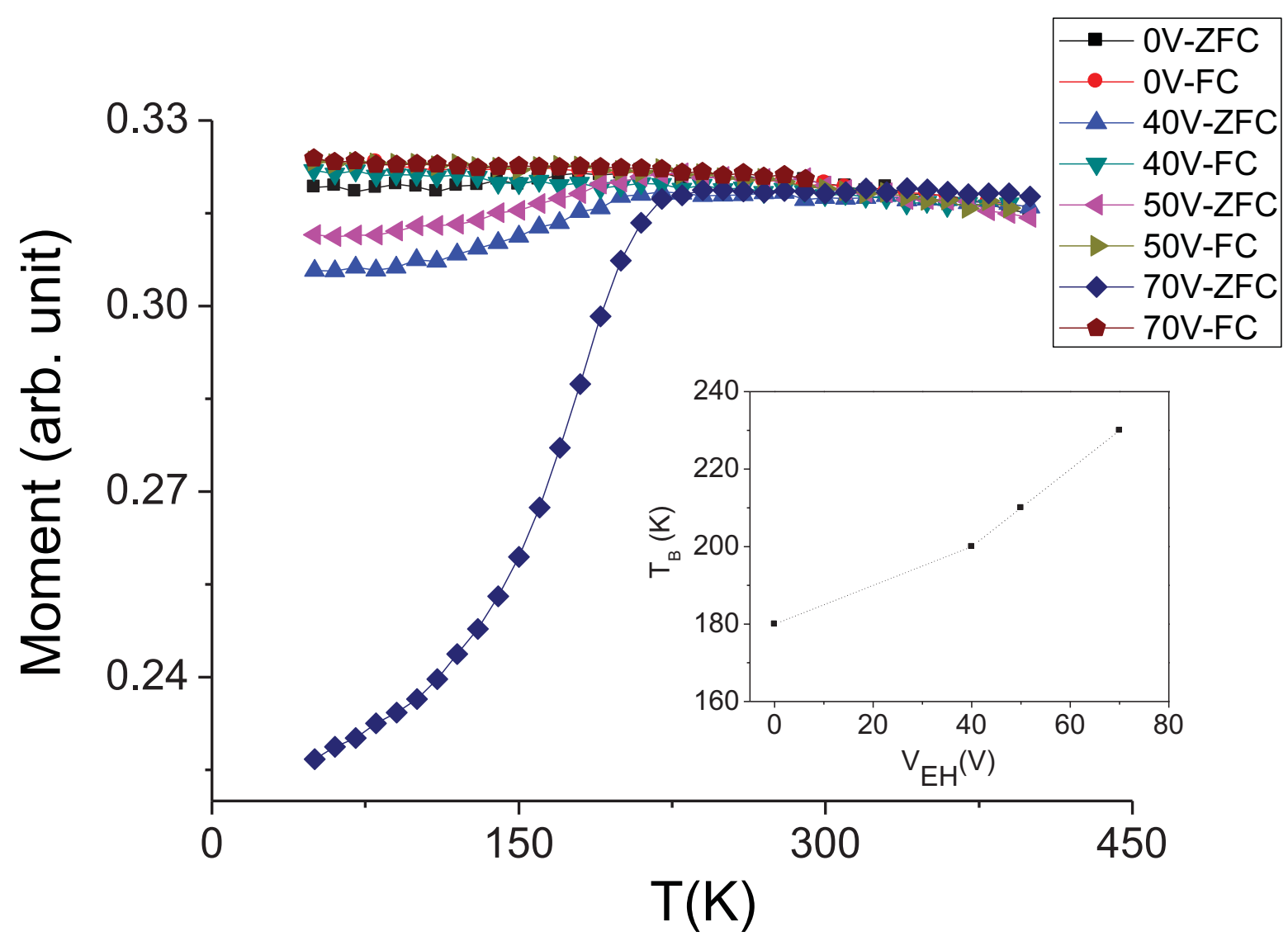


Fig. 4.

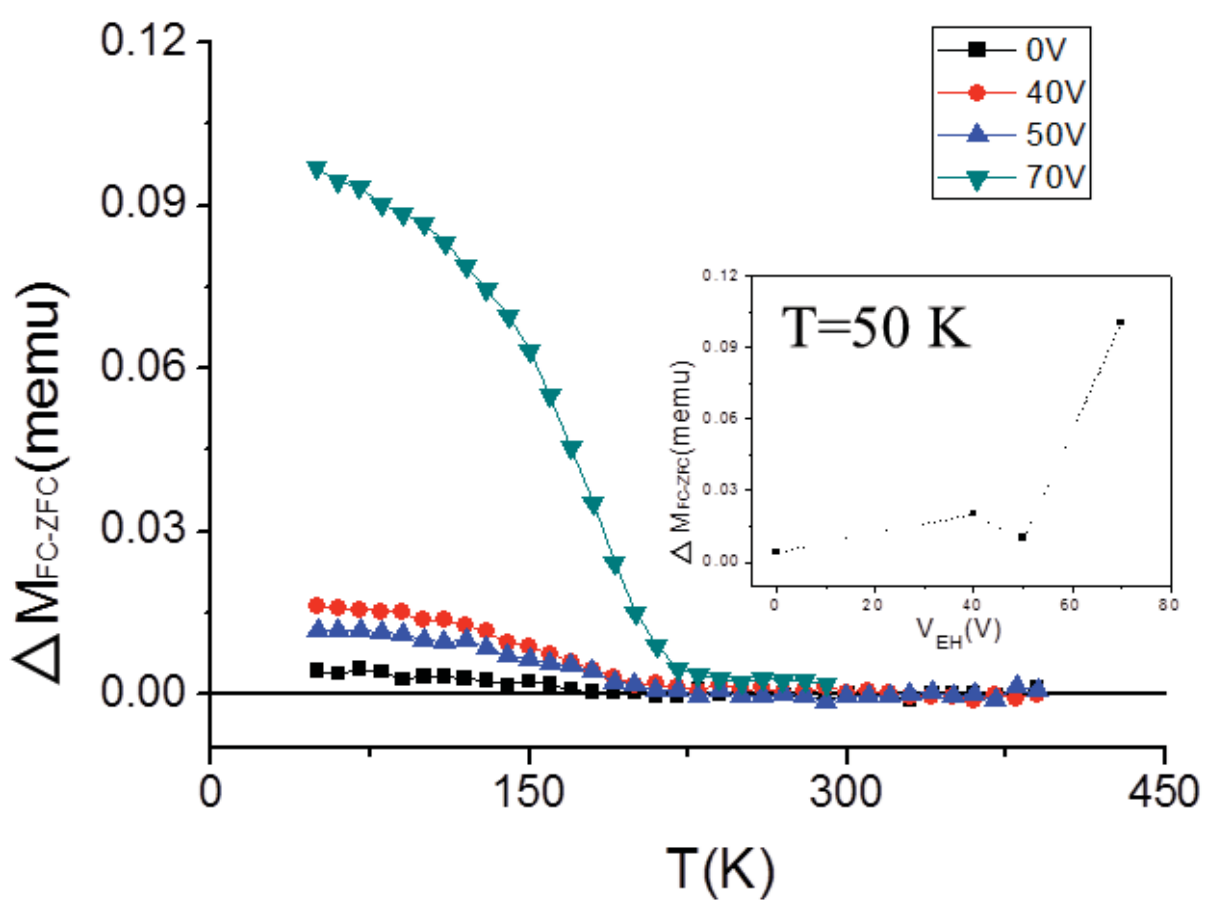

